\title{
Laminar plasma jets: Generation, characterization, and applications for materials surface processing*
}

\author{
W. X. Pan ${ }^{\ddagger}$, G. Li, X. Meng, W. Ma, and C. K. Wu \\ Institute of Mechanics, Chinese Academy of Sciences, Beijing 100080, China
}

\begin{abstract}
Nontransferred dc laminar plasma jets of pure argon were generated at atmospheric pressure, with a generator having an interelectrode insert. Associated with the experimental investigation, similarity theory was adopted to examine the arc voltage characteristics, thermal efficiency, and jet length change of the laminar plasma. Jet flow temperature and velocity were evaluated by various methods. The jet shows good stability, reproducibility, and regular flow field change as functions of generating parameters. Applications of laminar plasma jets for $\mathrm{ZrO}_{2}$ ceramics spray coating and remelt strengthening of metal surface were attempted. The results indicated favorite process efficiency and controllability of the laminar plasma heating.
\end{abstract}

Keywords:

\section{INTRODUCTION}

Nontransferred atmospheric dc plasma jets under turbulent flow condition have been widely used and much discussed. The laminar-flow plasma jet shows the characteristics of stable flow, low noise, and low temperature gradient along its axis $[1,2]$. These could be advantageous for materials processing usage, compared with a conventional turbulent plasma jet of much higher temperature gradient in the axial direction caused by the serious flow fluctuation and mixing of the surrounding atmosphere [3]. Furthermore, besides considerations for application, the laminar plasma jet can be an ideal object to correlate theoretical analysis or numerical simulation with the experimental work, owing to its favorite reproducibility and appreciably changed temperature and velocity patterns with the change of generating parameters.

The laminar plasma jet has never been much investigated nor widely used in the past. The reasons that handicapped its development could be some understanding which emphasized its shortcomings of low thermal efficiency [4], relatively complicated torch structure [1,4], narrow range of generating parameters, and delicate working state that might be easily disturbed by additional operations such as powder feeding in spraying. Therefore, this paper tries to provide a relatively complete outline of the laminar dc plasma jet by comprehensively summing up our related recent work.

\section{GENERATION OF ARGON LAMINAR-FLOW PLASMA AT ATMOSPHERIC PRESSURE}

Laminar plasma jets can be generated in relatively wide parameter ranges of arc current and gas flow rate with a torch of suitable structure [2]. The interelectrode insert between cathode and anode could

\footnotetext{
*Paper based on a presentation at $16^{\text {th }}$ International Symposium on Plasma Chemistry, held in Taormina, Italy, 22-27 June 2003. Other presentations are published in this issue, pp. 345-xxx.

¥Corresponding author
} 
play a role of limiting the arc root jumping and regulating the arc column length. Higher arc current allows higher gas flow rate at which no transfer to turbulent flow occurred. And the arc voltage increases simply with the increasing arc current and gas flow rate as shown in Fig. 1, in which the separate points were experimentally measured at arc currents of $100-200 \AA$ and gas flow rates of $1.5 \times 10^{-4}$ to $2.9 \times 10^{-4} \mathrm{~kg} / \mathrm{s}$.

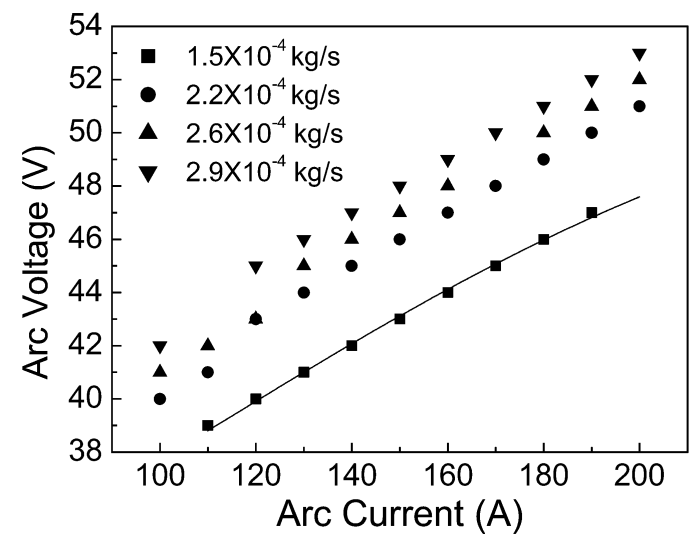

Fig. 1 Relationships between arc voltage and arc current of the laminar plasma generation. Data corresponding to the marks in the graph indicate the gas flow rates.

Thermal efficiency for the laminar plasma generation can reach $40 \%$ [2]. Figure 2a indicates that thermal efficiency also increases simply with increasing gas flow rate in the range of $1.7 \times 10^{-4}$ to $3.4 \times 10^{-4} \mathrm{~kg} / \mathrm{s}$, but changes with a little complex character as the increasing of arc current. It has a minimum value at arc current of about $160 \mathrm{~A}$, in spite of the different gas flow rate. In order to discuss the essential factor affecting the thermal efficiency, mean arc temperature was calculated according to Steenbeck's channel-model under our experimental condition of 4-mm arc channel diameter, and mean jet-flow temperatures at the anode exit were evaluated by measuring the jet power and the gas flow rate [2], obtaining the specific enthalpy and hence the mean gas temperature [5]. The channel model has no consideration on the effect of gas flow rate, and the result in Fig. $2 \mathrm{~b}$ shows that mean arc temperature rises from 13 600-18 $000 \mathrm{~K}$ as arc current changes from 100-200 A, between which heat conductivity of the argon gas has a maximum value at about $15000 \mathrm{~K}$ [5]. The points in Fig. $2 \mathrm{~b}$ are the mean gasflow temperature at gas flow rates of $2.2 \times 10^{-4} \mathrm{~kg} / \mathrm{s}, 2.6 \times 10^{-4} \mathrm{~kg} / \mathrm{s}$, and $2.9 \times 10^{-4} \mathrm{~kg} / \mathrm{s}$. It is inde-

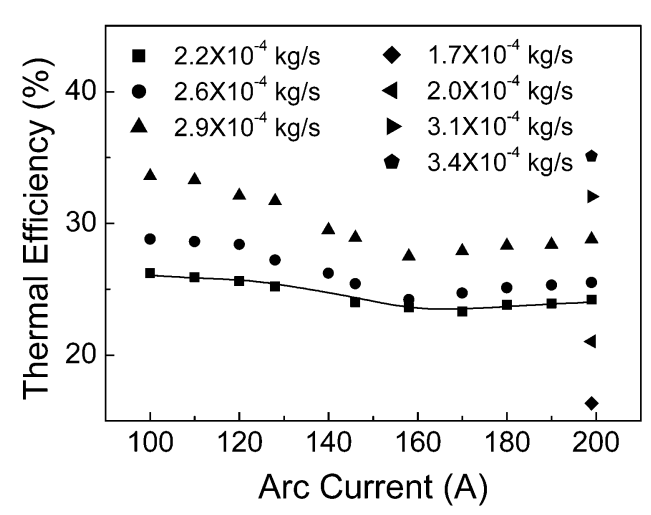

(a)

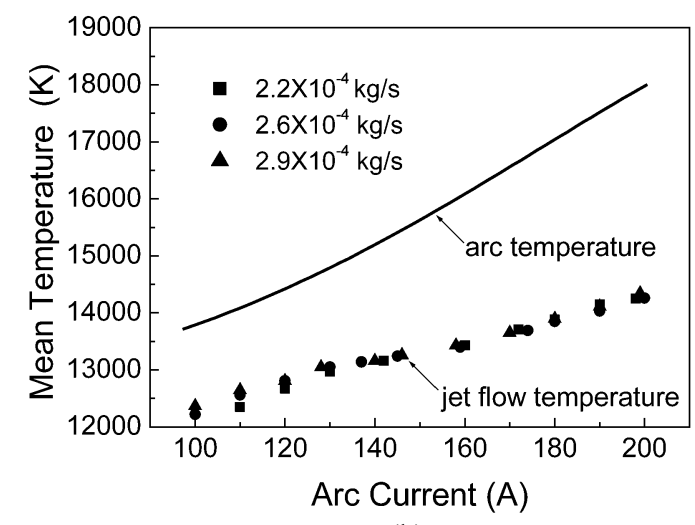

(b)

Fig. 2 Dependences of thermal efficiency (a) and mean arc temperature and mean jet-flow temperature at the torch exit (b) on the arc current. Data with the marks indicate the different gas flow rate. 
pendent of the gas flow rate and can be over $14000 \mathrm{~K}$ at arc current of $200 \mathrm{~A}$. These results indicate that the arc column seems to be stable and almost fully developed in the torch channel; thermal conductivity of the plasma working gas could play an important role in affecting thermal efficiency of the laminar-plasma generation when the arc channel is relatively long.

Reported relationships derived from the similarity theory associated with turbulent plasma generation in literature [6] are not suitable for describing the laminar plasma generation here. Thus, formulas in nondimensional form are derived according to the similarity theory and our experiment results. The measured points in Fig. 1 at gas flow rates of $2.2 \times 10^{-4} \mathrm{~kg} / \mathrm{s}, 2.6 \times 10^{-4} \mathrm{~kg} / \mathrm{s}$, and $2.9 \times 10^{-4} \mathrm{~kg} / \mathrm{s}$ were used to derive eq. 1 shown below for calculating arc voltage, and points in Fig. $2 \mathrm{a}$ at $2.6 \times 10^{-4} \mathrm{~kg} / \mathrm{s}$ and $2.9 \times 10^{-4} \mathrm{~kg} / \mathrm{s}$ were used to derive eq. 2 for calculating thermal efficiency of the laminar plasma generation:

$$
\begin{aligned}
& \frac{u d \sigma_{0}}{I}=1.38\left(\frac{\sigma_{0} h_{0} g d}{I^{2}}\right)^{-0.9}\left(\frac{g}{\mu_{0} d}\right)^{1.1}\left(\frac{\lambda_{0} T_{0} \sigma_{0} d^{2}}{I^{2}}\right)^{1.2} \\
& \frac{1-\eta}{\eta}=0.03\left(\frac{\sigma_{0} h_{0} g d}{I^{2}}\right)^{-1.9}\left(\frac{\sigma_{0} u d}{I}\right)^{3.6}\left(\frac{\lambda_{0} T_{0} \sigma_{0} d^{2}}{I^{2}}\right)^{0.6}\left(\frac{g}{\mu_{0} d}\right)^{0.2}\left(\frac{\lambda}{\lambda_{0}}\right)^{0.9}
\end{aligned}
$$

The characters $d, g, u, I$, and $\eta$ represent inner diameter of anode, gas flow rate, arc voltage, arc current, and thermal efficiency, respectively; the characters $\rho, \mu, \sigma, h, \lambda$, and $T$ represent density, viscosity, electrical conductivity, specific enthalpy, thermal conductivity, temperature of the argon gas, respectively; symbols with subscript 0 represent corresponding reference values. These formulas can predict the characteristics of plasma generation quite well within the parameter range that insures the laminar jet flow condition. For example, solid lines in Figs. 1 and 2 a show the calculated results with eqs. 1 and 2 to predict the current-voltage characteristics at gas flow rate of $1.5 \times 10^{-4} \mathrm{~kg} / \mathrm{s}$ and the thermal efficiency at $2.2 \times 10^{-4} \mathrm{~kg} / \mathrm{s}$, respectively. These indicate that the calculated results agreed well with the corresponding experimental values measured later.

\section{CHARACTERISTICS OF THE JET FLOW FIELD}

The pure argon laminar jet reached $550 \mathrm{~mm}$ in length at a gas flow rate of $3.4 \times 10^{-4} \mathrm{~kg} / \mathrm{s}$ and arc current of $200 \mathrm{~A}$, with a length-to-diameter ratio of over 70 [2]. Generally, the jet length of laminar plasma increases appreciably with increasing gas flow rate and arc current, except in the case where flow state transferred to turbulent condition. This is a distinguishing feature of the laminar plasma jet, compared with the turbulent jet of serious fluctuating and hardly any length change with the regulation of generating parameters. The different jet length could indicate the different flow field distribution, and the prolonged jet length could suggest a reduced mixing of the surrounding cold atmosphere. Three groups of measured points in Fig. 3 of the jet length generated at gas flow rates of $2.2 \times 10^{-4}$ to $2.9 \times 10^{-4} \mathrm{~kg} / \mathrm{s}$ were used to derive the eq. 3 for calculating the laminar jet length $(l)$ using the similarity theory:

$$
\frac{l}{d}=54.84\left(\frac{\sigma_{0} h_{0} g d}{I^{2}}\right)^{-2.1}\left(\frac{\sigma_{0} u d}{I}\right)^{-0.94}\left(\frac{\lambda_{0} T_{0} \sigma_{0} d^{2}}{I^{2}}\right)^{0.6}\left(\frac{g}{\mu_{0} d}\right)^{1.1}\left(\frac{\sigma_{0} g^{3}}{\rho_{0}^{2} I^{2} d^{3}}\right)^{0.6}
$$

Similarly, the solid line in Fig. 3 is the calculated result with eq. 3 to predict the jet-length change at gas flow rate of $1.5 \times 10^{-4} \mathrm{~kg} / \mathrm{s}$, and the calculated results agreed well with the experimental points measured later under the same conditions. One can hardly get a formula to describe the jet length change for the turbulent flow plasma. 


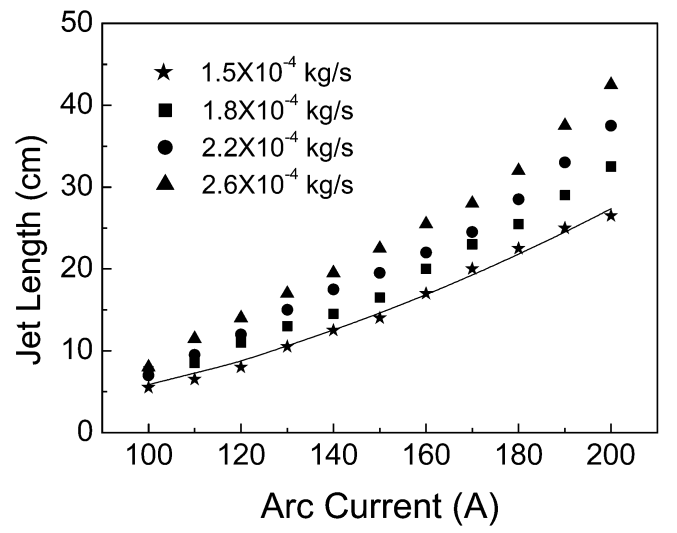

Fig. 3 Variation of the laminar jet length with arc current at different gas flow rate from $1.5 \times 10^{-4} \mathrm{~kg} / \mathrm{s}$ to $2.6 \times 10^{-4} \mathrm{~kg} / \mathrm{s}$.

The axial temperature changes smoothly with a gradient of about $55 \mathrm{~K} / \mathrm{mm}$ within the distance of $10 \mathrm{~mm}$ from the torch nozzle, and about $50 \mathrm{~K} / \mathrm{mm}$ in the distance of $10-80 \mathrm{~mm}$, as shown by the numerical simulation result [7] and the measured one in Fig. 4a by the spectrometric method [8]. These values are much lower than that of over $200 \mathrm{~K} / \mathrm{mm}$ for a turbulent plasma jet in its high-temperature region. The flow velocity is calculated by Bernoulli's equation according to the temperature and measured stagnation pressure using a pitot tube [8]. The average velocity gradient along the jet axis is about $8 \mathrm{~m} /(\mathrm{s} \cdot \mathrm{mm})$ within $80 \mathrm{~mm}$ from the torch nozzle. The maximum velocity, calculated by Bernoulli's equation and evaluated by the method according to jet mean temperature, gas flow rate, jet diameter of $4.7 \mathrm{~mm}$, and the relationship between mean and maximum velocities [7], agreed pretty well as shown in Fig. 4b. The maximum velocity at the torch exit increases with the increasing gas flow rate and arc current, and the values can be over $1000 \mathrm{~m} / \mathrm{s}$. That is, the laminar plasma jet can take a flow velocity almost the same as a conventional turbulent jet, and this is much higher than the generally considered maximum velocity of lower than $400 \mathrm{~m} / \mathrm{s}$ for a laminar-flow plasma jet $[9,10]$.

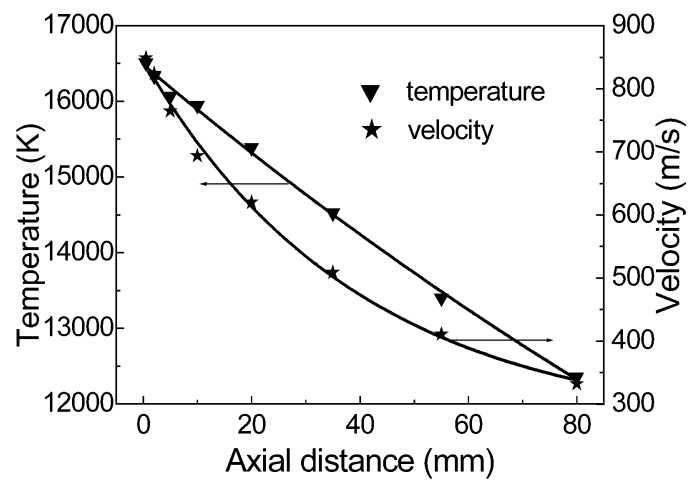

(a)

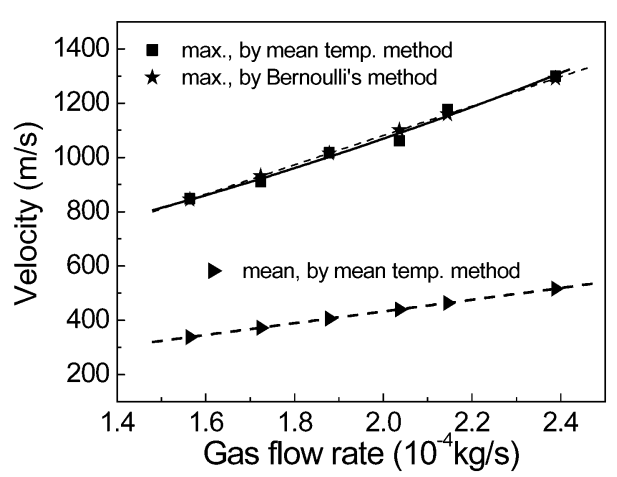

(b)

Fig. 4 Axial temperature and velocity distributions of the laminar plasma jet at gas flow rate of $1.5 \times 10^{-4} \mathrm{~kg} / \mathrm{s}$ and arc current of $170 \mathrm{~A}$ (a), and dependence of flow velocity at the torch exit on the gas flow rate (b).

The stable flow condition of the laminar plasma jet also makes it suitable to be characterized with dynamic measuring methods. Different types of heat flux probes were adopted $[11,12]$ or developed [8] to examine the heat flux distribution of the laminar plasma jet and its interaction effect with probe surfaces. The sweeping speed of the probe across the jet diameter can affect appreciably the measured heat 
flux value [8], and the measured value decreases with the decreasing thermal conductivity of powders coated in a thin layer on the copper probe surface [11].

\section{APPLICATIONS FOR MATERIALS SURFACE PROCESSING}

The stable high-energy intensity and low axial gradient of the laminar plasma jet brings about advantages for materials surface processing, owing to the enhanced controllability and reproducibility. Figure 5a shows surface morphologies of remelted and solidified trace of W-Mo-Cu cast iron treated with the laminar plasma heating at different arc currents from 182-195 A, when gas flow rate, distance from nozzle exit to the iron surface, and the moving speed of the piece across the plasma jet were kept constant. The trace size, both of its width and thickness, changed sensitively with the arc current, i.e., with the energy intensity of the plasma jet. The typical hardness change from the treated surface to the matrix is shown in Fig. 5b, and the relatively lower surface hardness is caused by the heat effect in overlap treating.

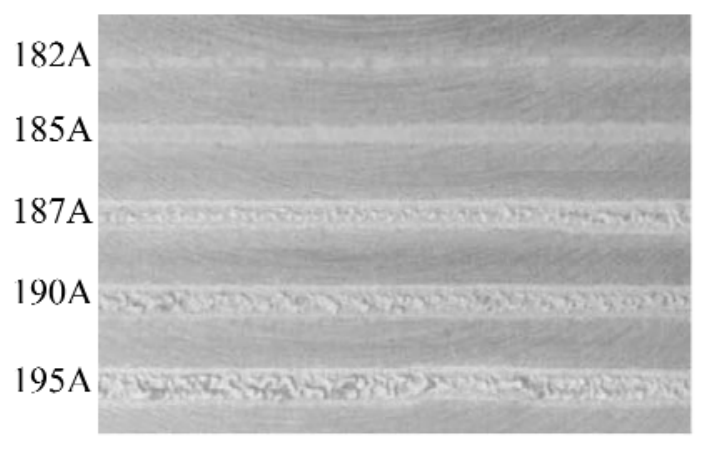

(a)

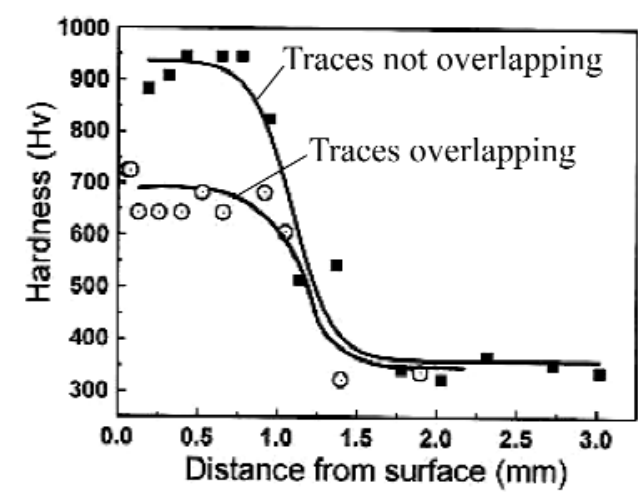

(b)

Fig. 5 Surface morphologies of remelted and solidified trace of W-Mo-Cu cast iron at different arc current from 182-195 A (a), and the hardness changes from the treated surface to the matrix (b).

Yttria-stabilized zirconia (YSZ) ceramic powder was sprayed in reduced [13] and atmospheric pressure laminar plasma jet. The long laminar jet flow could not be easily disturbed by the powder injection. If the feeding parameters do not match the jet condition, the powder can hardly be fed into the high-temperature region of the jet flow center as shown in Fig. 6a. A favorite heating can be obtained under suitable feeding conditions as shown in Fig. 6b, and YSZ powder of particle size under $75 \mu \mathrm{m}$ can be completely melted in the atmospheric laminar plasma jet of $10 \mathrm{~kW}$ input power, which is lower than half of the input power for a conventional turbulent plasma spraying of the same powder.

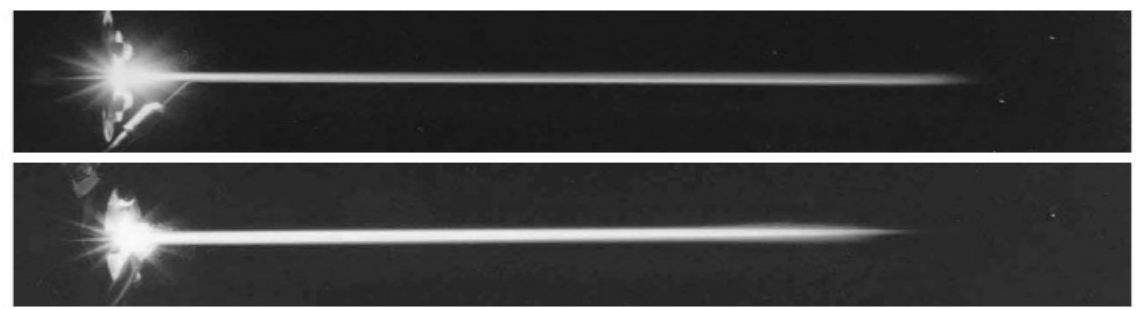

(a)

Fig. 6 The powder could not be fed into the high-temperature region of the jet flow center (a), and the powder particles were heated along the jet center (b). 


\section{CONCLUSIONS}

Laminar plasma jets can be generated in relatively wide parameter ranges of arc current and gas flow rate. Thermal efficiency increases simply with the increasing gas flow rate, and thermal conductivity of the working gas could play an important role in affecting thermal efficiency of the laminar-plasma generation. The mean flow temperature at the torch nozzle exit is independent of the gas flow rate and can be over $14000 \mathrm{~K}$ at arc current of $200 \mathrm{~A}$. The jet length of the laminar plasma increases appreciably with the increasing gas flow rate and/or arc current with good reproducibility, thus, the formula for calculating the laminar jet length is obtained with the help of similarity theory. The axial temperature gradient of laminar plasma jet is much lower than the case of a turbulent jet. Maximum velocity at the torch exit can be over $1000 \mathrm{~m} / \mathrm{s}$, almost the same as that of a conventional turbulent plasma jet. Laminarplasma remelt strengthening of the metal surface shows satisfied process controllability. YSZ ceramic powder of particle size under $75 \mu \mathrm{m}$ can be completely melted in the atmospheric laminar plasma jet of $10 \mathrm{~kW}$ input power.

\section{ACKNOWLEDGMENTS}

This work is financially supported by the National Natural Science Foundation of China with Project Nos. 59836220, 50336010, and 50276065.

\section{REFERENCES}

1. V. I. Kuz'min, O. P. Solonenko, M. F. Zhukov. Proc. of the $8^{\text {th }}$ National Thermal Spray Conference, p. 83, Houston, TX (1995).

2. W. X. Pan, W. H. Zhang, W. Ma, C. K. Wu. Plasma Chem. Plasma Process. 22 (2), 271 (2002).

3. E. Pfender. Thin Solid Films 238, 228 (1994).

4. K. Osaki, O. Fukumasa, A. Kobayashi. Vacuum 59, 47 (2000).

5. M. I. Boulos, P. Fauchais, E. Pfender. Thermal Plasmas 1, p. 391, Plenum Press, New York (1994).

6. O. I. Yas'ko. J. Phys. D: Appl. Phys. 2, 733 (1969).

7. W. X. Pan, W. H. Zhang, W. H. Zhang, C. K. Wu. Plasma Chem. Plasma Process. 21 (1), 23 (2001).

8. X. Meng, W. X. Pan, C. K. Wu. Proc. of $16^{\text {th }}$ Int. Symp. on Plasma Chemistry, Taormina (2003).

9. W. H. Zhang, W. X. Pan, C. K. Wu. Plasma Sci. Tech. 1 (1), 73 (1999).

10. X. Chen and Y. X. Gu. Proc. of $15^{\text {th }}$ Int. Symp. on Plasma Chemistry, p. 1045, Orleans (2001).

11. X. Meng, W. X. Pan, C. K. Wu. Chin. Phys. Lett. 20 (5), 685 (2003).

12. X. Meng, W. X. Pan, W. H. Zhang, C. K. Wu. Plasma Sci. Tech. 3 (5), 953 (2001).

13. W. Ma, W. X. Pan, G. Li, C. K. Wu. Proc. of $15^{\text {th }}$ Int. Symp. on Plasma Chemistry, p. 2609, Orleans (2001). 